\title{
Perception of Pharmacovigilance by Nurses and Midwives of the Cocody University Teaching Hospital in Abidjan
}

\author{
Balayssac Eric ${ }^{1,2}$, Tadjo Jean², Adon Auguste ${ }^{3}$, Ehouman Mocket ${ }^{4}$ \\ ${ }^{1}$ Clinical Pharmacology Service, University Teaching Hospital of Cocody, Abidjan, Ivory Coast \\ ${ }^{2}$ Department of Biochemistry, Physiology and Pharmacology, Training and Research Unit of the Medical Sciences of Abidjan, \\ Felix Houphouet Boigny University, Abidjan, Ivory Coast \\ ${ }^{3}$ Department of General and Digestive Surgery, University Teaching Hospital of Treichville, Abidjan, Ivory Coast \\ ${ }^{4}$ Clinical Research Service, Olopam Pharma and Research and Development, Abidjan, Ivory Coast \\ Email: *ebalayssac@yahoo.fr
}

How to cite this paper: Eric, B., Jean, T., Auguste, A. and Mocket, E. (2019) Perception of Pharmacovigilance by Nurses and Midwives of the Cocody University Teaching Hospital in Abidjan. Pharmacology \& Pharmacy, 10, 474-483.

https://doi.org/10.4236/pp.2019.1011039

Received: September 24, 2019

Accepted: November 2, 2019

Published: November 5, 2019

Copyright (c) 2019 by author(s) and Scientific Research Publishing Inc. This work is licensed under the Creative Commons Attribution International License (CC BY 4.0)

http://creativecommons.org/licenses/by/4.0/

Open Access

\begin{abstract}
Objective: To assess the perception on pharmacovigilance by the nurses and midwives at the University Teaching Hospital (CHU) of Cocody in 2017. Methodology: Descriptive and analytic cross-sectional study conducted in 17 services of the University Teaching Hospital (CHU) of Cocody using an anonymized and standardized questionnaire. Results: The response rate was $39.33 \%$ for the 86 nurses and 21 midwives with at least 10 years of professional experience (50.6\%). 57.94\% of the respondents $(\mathrm{n}=$ 62) have already heard about pharmacovigilance during their basic training $(40.18 \%, n=43)$. However, only $19.63 \%(21 / 107)$ of the respondents knew about the existence of a pharmacovigilance unit which they wrongly located to the pharmacy $(11 / 21)$ of the $\mathrm{CHU}$ of Cocody. $40.18 \%$ of respondents $(\mathrm{n}=$ 43) had previously experienced an adverse drug reaction that was reported (76.74\%, $\mathrm{n}=33)$ to a hierarchical supervisor $(60.60 \%, \mathrm{n}=20)$. The causes of non-reporting were either the frequent occurence $(4 / 10)$ or the benign nature $(2 / 10)$ of the adverse drug reaction. Specific actions to be taken $(37.38 \%$, $\mathrm{n}=40)$ and a feedback $(28.97 \%, \mathrm{n}=31)$ were the respondents' main expectations for the stimulation of the reporting system. They also wanted the pharmacovigilance monitors to regularly visit their services $(34.57 \%, \mathrm{n}=$ 37 ) and to provide them with the reporting forms $(30.84 \%, n=33)$. Conclusion: Our study has allowed us to highlight the lack of knowledge of the pharmacovigilance and to identify certain factors that could improve the perception of the pharmacovigilance by the nurses and the midwives in Ivory Coast.
\end{abstract}




\section{Keywords}

Perception, Pharmacovigilance, Nurses, Midwives, Hospital

\section{Introduction}

According to WHO, pharmacovigilance is defined as the science and activities related to the detection, evaluation, understanding and prevention of the risk of adverse effects and any other problems related to the use of the drug [1]. Although it is a well-established activity in industrialized countries, it encounters difficulties in sub-Saharan Africa in its implementation. In Côte d'Ivoire, a West African country, the absence of a National Pharmacovigilance Center (NPVC) hampers the setting up of a national system of pharmacovigilance [2] [3]. In this context, the Clinical Pharmacology Department of the University Teaching Hospital ( $\mathrm{CHU})$ of Cocody records and evaluates the reports of the adverse drug reactions (ADRs).

However, these reportings are conducted exclusively by doctors at the CHU of Cocody. Hence, the need to understand the perception of the pharmacovigilance by the nurses and the midwives who are the paramedical personnel in Côte d'Ivoire.

Our study was the first to focus on the perception of the pharmacovigilance by the nurses and midwives practicing at the $\mathrm{CHU}$ of Cocody. It was justified, on one hand by the fact that nurses and midwives have regulatory obligation like any other healthcare professionals to report ADR in Côte d'Ivoire [2]. On the hand, by the fact that in 2017, nurses and midwives accounted for the majority of health care workers in the Ivorian health system [4]. The overall objective of our study was to assess the perception on pharmacovigilance by the nurses and midwives practicing at the University Teaching Hospital (CHU) of Cocody in 2017. The specific objectives were to describe the professional characteristics of the nurses and the midwives, to determine their general knowledge on pharmacovigilance, to determine their expectations (following an ADR report) and lastly, to identify the measures to stimulate their spontaneous notification.

\section{Method}

From March 15, 2017 to April 05, 2017, we conducted a descriptive and analytical cross-sectional survey at the University Teaching Hospital (CHU) of Cocody in all drugs prescribing services (Ophthalmology, Pneumo-phtisiology, Digestive surgery, Urology, Stomatology, Otorhinolaryngology, Neurology, Rheumatology, Paediatric surgery, Traumatology, Gynecology, Hepato-gastroenterology, Intensive care, Paediatrics, X-ray (imaging) and a grouped-emergency services (Paediatric, Surgical, Gynecological and Medical).

\subsection{Study Population}

Our survey targeted the nurses and midwives practicing in 2017 in any of the 
hospital services where drugs were prescribed. From this source population, we selected from the administrative list of the paramedical staff at the CHU of Cocody a sample based on the oral consent and the physical presence. Indeed, periodic visits by one of physicians of pharmacology department according to an appointment calendars allowed, after the explanation of the questionnaire, to recruit the participants in their workplace. Thus, all nurses and midwives present during the study period regardless of their age, gender, nationality, year of professional experience as long as they have agreed to participate in the survey were included in the study. On the contrary, the nurses and the midwives employed in the selected services but absent (with the exception of those on night shifts) at the time of the survey or who did not give their consent or who did not complete the survey form were not included in the study.

\subsection{Study Process}

In a first step, we developed based on the literature reviews [5] [6] [7] [8], a standardized and anonymized questionnaire containing in the majority of cases open-ended (closed) questions. The questionnaire was designed on the classical model for assessing attitudes, knowledge and practice. It was, after validation at the Clinical Pharmacology Department, pre-tested in the Medical and Gynecological emergency services for improvement. Thereafter, the registrar of the Clinical Pharmacology Department made several rounds in the selected services to interview the nurses and midwives who were previously informed about the objectives of the study for the completion of the questionnaire. In some cases (lack of time, heavy workload, absence due to night shift, etc.), the questionnaires were given to the nurses and midwives for self-administration and then collected the following day. The perception of pharmacovigilance was evaluated from 13 questions grouped in 5 broad variables. It was:

- The professional characteristics (profession, name of the specific hospital service, and seniority in the position).

- General knowledge on pharmacovigilance (source of information, pharmacovigilance teaching hours in the basic training, existence and location of a pharmacovigilance unit at the $\mathrm{CHU}$ of Cocody, importance given to pharmacovigilance in practice).

- Reporting of adverse drug reactions (existence of ADRs in the service, types of adverse reactions reported, reporting methods, reasons for non-reporting).

- The expectations of nurses and midwives after reporting an ADR.

- Measures to improve the rate of reporting of ADR by the nurses and midwives.

\subsection{Statistical Analysis}

The data was analyzed using the EPI info7.4 software for the capturing of the information and the S.P.S.S. program. 17.0 (Statistical Package for the Social Sciences version 17.0) for statistical analysis. A Pearson Chi-square test was used to compare the results with a significance level of $5 \%$. 


\subsection{Ethical Considerations}

When collecting the data, we respected the anonymity of the nurses and midwives and ensured that their activities were not disrupted during working hours. Moreover, we obtained the oral agreement of the Head of the services and the Unit Care Supervisors (UCS) of the selected services. In addition, a written authorization from the Director of the Medical and Scientific Department of the University Teaching Hospital of Cocody was obtained before the beginning of the study. Finally, no healthcare provider completed the questionnaire under coercion.

\section{Results}

\subsection{Professional Characteristics of Nurses and Midwives}

Of the 272 paramedics (196 nurses and 76 midwives) surveyed, only $39.33 \%$ (86 nurses and 21 midwives) voluntarily answered the questions (Table 1). They mainly worked in the service of internal Medicine (58.46\%) and Surgery (52.11\%) and had in the majority of cases (50.6\%) a professional experience of less than 10 years (Table 2). The other primary information such as age, sex, specialty and place of residence were incorrectly entered on the questionnaire and could not be showed in a table.

\subsection{General Knowledge on Pharmacovigilance by Nurses and Midwives}

In our study, $57.94 \%$ (62/107) of paramedics (52 nurses and 10 midwives) had already heard of pharmacovigilance (Table 2), mainly during their basic training (43/107). However, only 5.60\% (6/107) of these respondents were satisfied with the volume of hours allocated to the pharmacovigilance module (Table 2). In addition, $19.63 \%$ (21/107) of respondents were aware of the existence of a pharmacovigilance unit (Table 2) that they had pointed to be inside the pharmacy (11/21) of the University Teaching Hospital of Cocody or at the Clinical Pharmacology

Table 1. Distribution of nurses and midwives by services.

\begin{tabular}{|c|c|c|c|c|c|}
\hline & \multicolumn{2}{|c|}{ Nurses $(n=196)$} & \multicolumn{2}{|c|}{ Midwives $(\mathrm{n}=76)$} & \multirow[b]{2}{*}{ Percentages } \\
\hline & Responses & Percentages & Responses & Percentages & \\
\hline Medicine ${ }^{* *}$ & $36 / 60$ & $60 \%$ & $02 / 05$ & $40 \%$ & $58.46 \%$ \\
\hline Surgery $^{* * *}$ & $33 / 64$ & $51.56 \%$ & $04 / 07$ & $57.14 \%$ & $52.11 \%$ \\
\hline Gynecology & $00 / 00$ & $00 \%$ & $12 / 36$ & $33.33 \%$ & $33.33 \%$ \\
\hline Pediatric & $06 / 17$ & $35.29 \%$ & $02 / 27$ & $0.07 \%$ & $18.18 \%$ \\
\hline Emergency service $^{*}$ & $11 / 55$ & $20 \%$ & $01 / 01$ & $100 \%$ & $2.42 \%$ \\
\hline Total & 86 & $43.87 \%$ & 21 & $27.61 \%$ & $39.33 \%$ \\
\hline
\end{tabular}

${ }^{\star}$ Emergency service: Emergencies of Medicine, Surgery, Gynecology and Pediatrics; ${ }^{\star *}$ Medicine: Pneumophtisiology, intensive care unit, Rheumatology, Gastroenterology, Neurology; ${ }^{\star * \star S u r g e r y: ~ T r a u m a t o l o-~}$ gy, Digestive Surgery, Urology, Ophthalmology, Oto-Rhino-Laryngology, Stomatology, Pediatric Surgery. 
Table 2. General knowledge on pharmacovigilance by paramedicals (nurses and midwives).

\begin{tabular}{|c|c|c|}
\hline Modalities & Number of Paramedical staff & Percentages \\
\hline \multicolumn{3}{|c|}{ Already heard about pharmacovigilance } \\
\hline Yes & 62 & $57.94 \%$ \\
\hline No & 45 & $42.06 \%$ \\
\hline Total & 107 & $100 \%$ \\
\hline \multicolumn{3}{|c|}{ Source of information } \\
\hline Initial formation & 43 & $40.18 \%$ \\
\hline Colleague & 11 & $10.28 \%$ \\
\hline Media & 4 & $3.73 \%$ \\
\hline Physician & 2 & $1.86 \%$ \\
\hline Book & 1 & $0.93 \%$ \\
\hline Training workshop & 1 & $0.93 \%$ \\
\hline No answers & 45 & $42.05 \%$ \\
\hline Total & 107 & $100 \%$ \\
\hline \multicolumn{3}{|c|}{ Volume of hours to pharmacovigilance } \\
\hline Enough & 6 & $5.60 \%$ \\
\hline Not enough & 101 & $94.3 \%$ \\
\hline Total & 107 & $100 \%$ \\
\hline \multicolumn{3}{|c|}{ Existence of a pharmacovigilance unit at Cocody teaching hospital } \\
\hline Yes & 21 & $19.63 \%$ \\
\hline No & 86 & $80.37 \%$ \\
\hline Total & 107 & $100 \%$ \\
\hline \multicolumn{3}{|c|}{ Importance of pharmacovigilance } \\
\hline Not important & 4 & $3.73 \%$ \\
\hline Little important & 12 & $11.21 \%$ \\
\hline Important & 23 & $21.49 \%$ \\
\hline Very important & 52 & $48.59 \%$ \\
\hline No answers & 16 & $14.95 \%$ \\
\hline Total & 107 & $100 \%$ \\
\hline \multicolumn{3}{|c|}{ Seniority in the profession } \\
\hline $0-5$ years & 31 & $28.97 \%$ \\
\hline $6-10$ years & 23 & $21.49 \%$ \\
\hline $11-15$ years & 17 & $15.88 \%$ \\
\hline$>15$ years & 36 & $33.64 \%$ \\
\hline Total & 107 & $100 \%$ \\
\hline
\end{tabular}

Department (10/21). Furthermore, the paramedics (75/107) found pharmacovigilance important $(21.49 \%)$ or very important $(48.59 \%)$ in their daily practice (Table 2). 


\subsection{Reporting of Adverse Events by Nurses and Midwives}

In our survey, $40.18 \%(43 / 107)$ of the paramedics had already come across an adverse event (Table 3), mainly an adverse drug reactions (32/43). They reported these events in $76.74 \%$ (33/43) of the cases to a hierarchical supervisor

Table 3. Reports of adverse event by nurses and midwives.

\begin{tabular}{|c|c|c|}
\hline Modalities & Number of Paramedical staff & Percentages (\%) \\
\hline \multicolumn{3}{|c|}{ Have you ever experienced an adverse event? } \\
\hline Yes & 43 & 40.18 \\
\hline No & 64 & 59.81 \\
\hline Total & 107 & 100 \\
\hline \multicolumn{3}{|c|}{ Adverse event related to } \\
\hline Drug & 32 & 74.41 \\
\hline Equipment & 6 & 13.95 \\
\hline Reagent & 3 & 6.97 \\
\hline Labile blood product & 2 & 4.65 \\
\hline Total & 43 & 100 \\
\hline \multicolumn{3}{|c|}{ Was an adverse event declared? } \\
\hline Yes & 33 & 76.74 \\
\hline No & 10 & 23.25 \\
\hline Total & \multicolumn{2}{|l|}{43100} \\
\hline \multicolumn{3}{|c|}{ If yes, did you report it? } \\
\hline To a superior & 20 & 60.60 \\
\hline To the staff meeting & 6 & 18.18 \\
\hline In the patient's file & 5 & 15.15 \\
\hline To a colleague & 1 & 3.03 \\
\hline To the drugstore & 1 & 3.03 \\
\hline A the service of Pharmacology & 00 & 00 \\
\hline At the National Transfusion Center & 00 & 00 \\
\hline To pharmaceutical companies & 00 & 00 \\
\hline Total & 33 & 100 \\
\hline \multicolumn{3}{|c|}{ If no, reasons for non-declaration } \\
\hline Fréquent event & 4 & 44.44 \\
\hline Bénin event & 2 & 22.22 \\
\hline Known event & 1 & 11.11 \\
\hline Not important event & 1 & 11.11 \\
\hline Lack of time & 00 & 00 \\
\hline No reason & 1 & 11.11 \\
\hline Total & 09 & 100 \\
\hline
\end{tabular}


(20/33). The main causes of non-reporting of adverse drug reactions (Table 3 ) were related to their frequent occurence $(4 / 10)$ or their benign nature $(2 / 10)$.

\subsection{Expectations and Measures to Stimulate Spontaneous Notification}

Specific instructions such a code of conduct (37.38\%) and a feedback after reporting $(28.97 \%)$ were the main expectations of our respondents (Table 4 ). They also wanted a regular visit of the pharmacovigilance monitors in their services $(34.57 \%)$ and the provision of the reporting forms to stimulate a spontaneous reporting of adverse drug reactions (Table 4).

\section{Discussion}

The spontaneous notification is based solely on the will of the healthcare professionals, despite its mandatory nature in many countries, particularly in Côte d'Ivoire [1] [2]. It is, therefore, associated with the perception on pharmacovigilance by the same professionals. Our study had some limitations mainly related to how the data were collected (self-administered questionnaire or administered by the registrar of pharmacology) and the availability of paramedical personnel. However, it allowed us to collect 107 responses (39.33\%) out of 272 total administered questionnaires. This response rate, lower than what is reported in the literature [5]-[10] highlights the difficulties encountered during the data collection.

Table 4. Expectations and steps to be taken to stimulate reporting by nurses and midwives.

\begin{tabular}{|c|c|c|}
\hline Variables & Number of Paramedical staff & Percentages $(\%)$ \\
\hline \multicolumn{3}{|l|}{ Expectations after reporting } \\
\hline Feedback & 31 & 28.97 \\
\hline A withdrawal from marketing & 13 & 12.14 \\
\hline A health alert & 15 & 14.01 \\
\hline Precise management & 40 & 37.38 \\
\hline A modification of the instructions & 8 & 7.47 \\
\hline Unspecified & 00 & 00 \\
\hline Total & 107 & 100 \\
\hline \multicolumn{3}{|l|}{ Measures to stimulate reportings } \\
\hline Creation of a website & $11(10.28)$ & 10.28 \\
\hline Availability of declaration forms & $33(30.84)$ & 30.84 \\
\hline Regulars visits of the animators in the services & $37(34.57)$ & 34.57 \\
\hline Feedback with precise management & $26(24.29)$ & 24.29 \\
\hline Newsletter to prescribers & 00 & 00 \\
\hline Total & 107 & 100 \\
\hline
\end{tabular}




\subsection{Socio-Professional Characteristics of the Nurses and Midwives}

In our study, the response rate of the paramedics varied significantly according to the profession (nursing or midwifery) $\left(\mathrm{Chi}^{2}=6.058\right.$, $\left.\mathrm{ddl}=1, \mathrm{P}<0.02\right)$ and the service in which they are working $\left(\mathrm{Chi}^{2}=18.634, \mathrm{ddl}=4, \mathrm{P}<0.001\right)$. This could explain the various level of their knowledge on pharmacovigilance. In addition, most of our paramedics (54/107) had a professional seniority of less than 10 years. This was not reported in several studies [5] [6] [7] [8] [9] in which the majority of nurses interviewed had more than 11 years of working experience.

\subsection{Knowledge of the Pharmacovigilance by the Nurses and Midwives}

In our survey, $57.94 \%(62 / 107)$ of paramedics had already heard of the term pharmacovigilance mainly during their basic training (Table 2). However, the pharmacovigilance teaching hours considered insufficient and reported by $94.39 \%$ $(101 / 107)$ of the paramedics reflects the need for a continuous training. There was no significantly different relationship between having previously heard about pharmacovigilance and nurse or midwife status $(\mathrm{p}=0.14)$ and hospital service ( $\mathrm{p}=0.124)$. On the other hand, there was a significant difference between having previously heard about pharmacovigilance and professional experience $(\mathrm{p}=0.028)$. This professional experience was not statistically related to declaring pharmacovigilance as an important activity $(\mathrm{p}=0.61)$.

Apart from that, $80.37 \%(86 / 107)$ of the paramedics in our study were unaware of the existence of the pharmacovigilance unit and wrongly located it at the pharmacy (11/21). This could be a barrier to reporting of the adverse drug reactions at the CHU of Cocody. Our results were comparable to those of a Saudi study [10] in which $62.5 \%$ of healthcare professionals said they did not know the term "pharmacovigilance". Furthermore, in two (2) Italian and Portuguese studies [6] [7], the nurses did not know the existence of the national pharmacovigilance system in $50 \%$ and $58.1 \%$ of cases respectively.

\subsection{Declaration of the Nurses and Midwives}

In our work, the ignorance of the reporting procedures was another factor that could negatively influence the perception on pharmacovigilance. In fact, the majority of the 33 respondent paramedics ( $n=20,60.60 \%$ ) had reported the adverse drug reactions to their hierarchical supervisor and none of these events were reported to the pharmacovigilance unit. This did not comply with the Regulatory Act that creates the national pharmacovigilance system in Côte d'Ivoire [2]. Under these conditions, a special emphasis should be made on the procedural aspects of the Act if the desire is to increase the number of adverse drug reactions reporting at the $\mathrm{CHU}$ of Cocody. Furthermore, in our survey, 4 out of 10 respondent paramedics did not report the adverse drug reactions because of their frequent occurrence (Table 3 ). This was not justified because all adverse drug reactions should have been reported, especially those that are unexpected 
or serious [2]. In an Italian study [6], the poor knowledge of the pharmacovigilance system, the fear of conflicts with doctors and the fear of legal reprisals were the main reasons for the under-reporting of the adverse drug reactions by nurses.

\subsection{Expectations of the Nurses and Midwives and Actions to Be Taken}

In our study, paramedics mainly expected a precise code of conduct and a feedback on a reported event (Table 4). In addition, to stimulate a spontaneous notification, most of the respondent paramedics had suggested a regular visit of the pharmacovigilance monitors in their different services $(34.57 \%, \mathrm{n}=37)$ and the provision of the reporting forms $(30.84 \% ; n=33)$ as shown in Table 4 . These expectations and measures expressed by the paramedics show their interest to see the pharmacovigilance been practiced at the CHU of Cocody. This interest should be taken into account in the organization of awareness and continuous training in the practice of pharmacovigilance in Côte d'Ivoire (Ivory Coast). In fact, regular visits by pharmacovigilance monitors to hospital services could help staff paramedic to detect adverse drug reactions, to identify and resolve problems encountered by nurses and midwives in process of declaration of adverse drugs reaction and develop a special relationship with them. This attitude, coupled with the disponibility of the declaration forms, could positively influence the perception of pharmacovigilance by paramedical staff. Overwise, Feedback with precise management is an important device in pharmacovigilance. This feedback, which also mentions the responsibility or not of the suspected drug (s), should be included in the patient file and thus testify to the occurrence of the adverse drugs reaction.

\section{Conclusion}

Our study allowed us to identify factors that may influence the perception of the pharmacovigilance by the nurses and midwives. The main barrier to reporting of the adverse drug reactions at the $\mathrm{CHU}$ of Cocody were an insufficient hourly volume in pharmacovigilance at initial training, the ignorance of the existence of the pharmacovigilance unit and the lack of knowledge of reporting procedures. This could be improved with a continuous training of these paramedical personnel, regular contact with the pharmacovigilance monitors and a specific code of conduct to be followed in case of any occurrence of adverse drug reactions.

\section{Conflicts of Interest}

The authors declare no conflicts of interest regarding the publication of this paper.

\section{References}

[1] World Health Organization (1972) International Drug Monitoring: The Role of Na- 
tional Centers. World Health Organ Tech. Rep. Ser. 498, 1-25.

[2] Ministry of Health and Public Hygiene (2010) Act No. 210/MSHP/CAB of 24 November 2010 Amending Decree No. 16MSHP/CAB of 10 February 2009 Establishing, Organizing and Operating the National System of Pharmacovigilance.

[3] Miremont-Salamé, G., Théophie, G., Haramburu, F. and Bégaud, B. (2016) Causality Assessment in Pharmacovigilance: The French Method and Its Successive Updates. Therapie, 71, 179-186. https://doi.org/10.1016/j.therap.2016.02.010

[4] Ministry of Health and Public Hygiene, Côte d'Ivoire (2016) Annual Report on the Sanitary Situation RASS 2016. https://www.dipe.info

[5] Vural, F., Ciftci, S. and Vural, B. (2014) The Knowledge, Attitude and Behaviors of Nurses about Pharmacovigilance, Adverse Drug Reaction and Adverse Event Reporting in a State Hospital. Northern Clinics of İstanbul, 1, 147-152. https://doi.org/10.14744/nci.2014.41636

[6] De Angelis, A., Giusti, A., Colaceci, S., Vellone, E. and Alvaro, R. (2015) Nurses' Reporting of Suspect Adverse Drug Reactions: A Mixed-Methods Study. Annali dell Istituto Superiore di Sanità, 5, 277-283.

[7] Mendes Marques, J.I., Polónia, J.M., Figueiras, A.G., Costa Santos, C.M. and Herdeiro, M.T. (2016) Nurses' Attitudes and Spontaneous Adverse Drug Reaction Reporting: A Case-Control Study in Portugal. Journal of Nursing Management, 24, 409-416. https://doi.org/10.1111/jonm.12337

[8] Gangadhar, M. and Guruppanavar, D. (2012) Assessment of Knowledge, Attitude and Perception of Pharmacovigilance among Nurses in a Rural Tertiary Care Center. International Journal of Basic \& Clinical Pharmacology, 4, 1009-1012. https://doi.org/10.18203/2319-2003.ijbcp20150883

[9] Vallano, A., Cereza, G., Pedros, C., et al. (2005) Obstacles and Solutions for Spontaneous Reporting of Adverse Drug Reactions in the Hospital. British Journal of Clinical Pharmacology, 60, 653-658. https://doi.org/10.1111/j.1365-2125.2005.02504.x

[10] Noor, B.A. (2016) Healthcare Professionals' Awareness and Knowledge of Adverse Drug Reactions and Pharmacovigilance. Saudi Medical Journal, 37, 1359-1364. https://doi.org/10.15537/smj.2016.12.17059 